\title{
SOBRE LA UTILIDAD E INUTILIDAD DE LA CATEGORÍA NUEVA NOVELA HISTÓRICA
} ON THE UTILITY AND INUTILITY OF THE NEW HISTORICAL NOVEL CATEGORY.

\section{María Loreto Contreras Godoy*}

Rec.: 15-04-2021. Acept.: 21-05-2021. Publ.: 30-06-2021

DOI: http://doi.org/10.29035/ucmaule.60.30

\section{RESUMEN}

Este estudio es una revisión crítica de la categoría Nueva Novela Histórica propuesta por Seymour Menton el año 1993. Se plantea que el marco de lectura implicado en esta categoría relevaría excesivamente las operaciones deconstructivas de estas novelas, limitando su potencial estético y crítico a su capacidad de desmantelar el discurso oficial del historicismo. Se propone, por lo tanto, ampliar sus potencialidades de significación, incluyendo su capacidad de rehacer el pasado, multiplicándolo, mostrándolo como siempre capaz de ser reinventado y revitalizando así su propia historicidad. Para esto se recurre a la teoría de la novela histórica de Lukács y de la caracterización de la vida de los signos en el texto novelístico que proponen autores/as como Noé Jitrik, Antonio Candido y Julia Kristeva.

Palabras clave: Narrativa histórica latinoamericana, novela histórica.

* Universidad de Chile, profeloretocontreras@gmail.com 


\section{ABSTRACT}

This study is a criticism review of the New Historical Novel category proposed by Seymour Menton in 1993. It is suggested that the implied reading frame in this category would excessively show the deconstructive operations of this novels, limiting their estetic and criticism potential to their capacty of dismantle the official discourse of historicism. It is proposed, therefore, extend its potential meanings, including their ability to rework the past, multiplying it, showing as always capable of being reinvented and thus revitalizing its own historicity. To do this, it is resorted to historical novel theory of Lukács and to the characterization of the live of the signs in the novels that proposed by authors such as Noé Jitrik, Antonio Candido and Julia Kristeva.

Key words: Latin American historical narrative, historical novel.

\section{INTRODUCCIÓN}

Para precisar este grado y, sobre su base, el límite desde el cual lo pasado ha de olvidarse, para que no se convierta en sepulturero del presente, habría que saber con exactitud cuánta es la fuerza plástica de un individuo, de un pueblo, de una cultura. Me refiero a esa fuerza para crecer desde la propia esencia, transformar y asimilar lo que es pasado y extraño, cicatrizar las heridas, reparar las pérdidas, rehacer las formas destruidas.

(Nietzsche, 1994, p. 76)

En 1874 Nietzsche publica su Segunda consideración intempestiva: Sobre la utilidad y los perjuicios de la historia para la vida. El adjetivo usado en el título -intempestivo- es fundamental, puesto que evoca un acto realizado de manera inoportuna. ¿Qué implica entonces este gesto que fuera de lugar predica sobre lo beneficioso y lo perjudicial de la historia para la vida? Es un gesto inoportuno hablar de la inutilidad de la historia para la sociedad occidental moderna que ha hecho de esta una categoría fundamental para su autocomprensión. Y más aún lo es hoy, momento en el que la historiografía oficial no promueve el olvido, sino el recuerdo de un pasado que borra lo que la postura hegemónica considera como insignificante. Se borra de la memoria el hecho de que la guerra, la violencia, la sangre y sus cadáveres constituyen el suelo del presente que habitamos. En este sentido, lo que hoy vivimos es, como señala Pablo Aravena (2009), una época que consume el pasado. Entonces, cuando la industria 
cultural promueve como nunca el consumo de la historia con series sobre Roma, los carteles de narcotráfico, canales de documentales, películas que se dan el lujo de fantasear con personajes emblemáticos', e incluso novelas históricas casi siempre bajo el formato de la novela sentimental, es preciso retomar la reflexión sobre la utilidad e inutilidad de la historia. Esta tarea entraña reconsiderar nuestra relación no sólo desde el discurso que versa sobre ella, sino también desde el nexo con el pasado que posibilitaría nuestra praxis actual. En tanto la historia es praxis Nietzsche puede defender la necesidad de olvidar para crear. Se entiende que lo que se olvida no es la propia historia, sino el discurso que ha jerarquizado y objetivado en una escala de valores aquello que es "grande" diferenciándolo de aquello que por "pequeño" no merece la pena ser recordado. Eternizar esta escala de valores es querer detener el flujo de la libre creatividad -deseo perjudicial para el propio desarrollo de la historia. De este modo, el olvido productivo nietzscheano es imprescindible para evitar que las ideas que tenemos sobre el desarrollo histórico se transformen en valores universales y atemporales. Esta sobrevaloración de un saber sostendría el oculto anhelo ideológico de detener acciones alternativas, argumentando haber alcanzado un estado acabado del desarrollo humano en el capitalismo y los estados nacionales. El sentido crítico entonces debe también examinar sus propios presupuestos; no vaya a ser que estemos cristalizando en el discurso aquello que de antemano creemos valioso y, con ello, pasemos por alto lo que la creatividad está constantemente produciendo.

La intención de iniciar este artículo sobre la categoría de Nueva novela histórica (en adelante $\mathrm{NNH}$ ) con la defensa que Nietzsche hace del olvido, es examinar los presupuestos que han llevado a ciertos autores a leer una serie no menor de novelas latinoamericanas contemporáneas a través de un aparato de categorías analíticas y desde una clara noción del carácter político de dicha narrativa. El propósito es olvidar lo que se ha hecho y poder tener un marco nuevo para leer dichas obras. Dedicaremos este estudio a la observación analítica de los límites, las utilidades y las naturalizaciones que ha desarrollado la línea de investigación en torno a la categoría NNH. En este sentido, lamentamos no poder hacer un análisis más acucioso de los textos narrativos, pues en esta ocasión nos limitaremos a la discusión teórica y categorial en el que las alusiones a algunas obras servirán de apoyo, sin que por eso no sean necesario otros estudios que profundicen en el análisis textual desde lo que aquí se propone.

1 Abundan ejemplos de este tipo. Un caso llamativo que combina un personaje emblemático de la historia estadounidense y el género de moda entre los adolescentes, esto es, las novelas de vampiro, es la película "Abraham Lincoln, cazador de vampiros". Esta representa un caso paradigmático de lo que Pablo Aravena (2009) llama "consumo de la historia", en tanto esta última se representa como mero trasfondo o ambiente de conflictos amorosos o estructuras de acción propias del género de la aventura, el terror y el suspenso. Una mezcla que resulta en películas, novelas y series producidos por la industria cultural y con un claro carácter pop, que los convierte en atractivos objetos de consumo. 
Es importante, por lo demás, destacar que, ante la creatividad olvidadiza de la industria cultural, el juicio crítico emergido de los estudios literarios se ha enfocado en el carácter negativo de la crítica que construiría la NNH. En otras palabras, hemos descrito, analizado e interpretado tan acuciosamente los alcances y utilidad de la desestabilización crítica de los discursos hegemónicos y oficiales de las novelas históricas contemporáneas, que se hace necesario traer de vuelta la dimensión positiva de la creación en todas sus formas. En este sentido, entenderemos que la novela histórica es una categoría que no sólo representa un pasado, sino que también hace algo con él.

\section{GÉNESIS DE LA CATEGORÍA NOVELA HISTÓRICA}

György Lukács (1971) fue el primer teórico en desarrollar un trabajo profundo sobre la categoría de novela histórica. Su trabajo se sitúa desde los orígenes románticos de este género, cuando la novela entabla una relación estrecha con los acontecimientos históricos. La emergencia de esta preocupación por lo histórico se extiende hasta nuestros días, deviniendo en discusión crítica que ha llegado a plantear la relación de la novela con lo histórico y con el discurso historiográfico como un marco de legibilidad de ciertas obras. De este modo, el carácter histórico de ciertas novelas se ha transformado en una posibilidad crítica para valorar ciertos textos desde su carácter político. Este carácter estaría dado por su capacidad de poner en crisis el estatuto epistemológico de otros campos disciplinarios, como lo son la historiografía y la sociología. En esta perspectiva, parece necesario revisar dicho marco de legibilidad del carácter histórico de la novela, pues es su devenir en una figura diferente a su referente histórico y factual, lo que podríamos definir como fundamento de la relación de la literatura con la historia. Para poder observar lo histórico de una novela hace falta también que el aparato crítico sea sensible a esa historicidad, pues se corre el peligro de darle densidad ética y estética a aquello que surge desde nuestra jerarquía de valores, opacando las posibilidades para ver lo singular, olvidar lo aprendido y dejar aparecer la creación en todo su alcance y necesidad históricos.

En este sentido, el mismo Lukács intenta generar el punto de anudamiento de lo que para el teórico argentino Noé Jitrik (1995) es un oxímoron: novela e historia; puesto que la novela es una modalidad textual que implica la invención imaginaria de historias, la novela histórica tiene contradictoriamente como condición de existencia el vínculo con el orden de los hechos efectivamente acontecidos: es una historia de una historia. Se anudan, pues, imaginación poética y referentes históricos. Este anudamiento es intencionado por las posibilidades productoras de la imaginación novelesca 
del Romanticismo, pero que, más allá del momento de su génesis, ha tenido una evolución en el tiempo que nos lleva a reflexionar sobre esta categoría en la América Latina actual. Por esta razón, podríamos decir que este anudamiento -entre historia y ficción- es un fenómeno ya clásico para la novela moderna. Para Lukács, a partir de la importancia que adquiere la historia en la filosofía hegeliana como el lugar privilegiado en el que el Espíritu se desenvuelve como práctica de la libertad humana, tendría también una importancia central como el lugar de articulación de la conciencia del poder y su ejercicio efectivo:

El pensamiento de las épocas anteriores oscilaba dentro de la antinomia cuyos términos eran una concepción fatalista y legal de todo suceder histórico y una sobrevaloración de las posibilidades de intervenir conscientemente en la evolución de la sociedad. [...] Hegel, en cambio, considera la historia como un proceso movilizado de un lado por las fuerzas motrices internas de la historia, y cuyo efecto, por el otro, se extiende a todos los fenómenos de la vida humana, incluido el pensamiento. Considera la totalidad de la vida humana como un gran proceso histórico. (1971. p. 27)

De este modo, para Lukács lo histórico es una propiedad de la praxis humana y en consecuencia toda actividad está marcada por el signo de su época y por todo el devenir que ha llevado a ella, partiendo por la novela romántica de Walter Scott, para terminar con la novela del humanismo democrático. Como no nos vamos a detener a examinar la obra teórica de Lukács, bastará que saltemos rápidamente hacia algunas consideraciones sobre este trabajo que algunos teóricos de la NNH han pasado por alto.

En primer lugar, Lukács reconoce que la relación entre ficción e historia elabora la dimensión vital y activa de lo histórico que la historiografía como disciplina diferenciada no logra hacer, por lo que para el teórico húngaro el conocimiento de lo histórico no es sólo competencia de la historiografía, sino que concierne a toda actividad humana.

En segundo lugar, sería inapropiado hablar de una novedad histórica (NNH) si aceptamos que lo histórico es el desarrollo infinito en el tiempo de actividades humanas finitas. La diferencia, entonces, sería el rasgo propio del devenir histórico. Esto implica que dicho devenir podría entenderse como la actividad de seres mortales que, recordando su pasado, conceden a la existencia del futuro la necesidad de su actuación en el presente. En este sentido, hablar de novedad de lo histórico no es sino otro nombre para la aparición de su signo más propio: el cambio, la muerte, lo finito, lo provisorio. En la revisión que hace Lukács queda de manifiesto que esta relación con la historia en la novela romántica no es nunca igual a sí misma, en tanto es precisamente el devenir 
temporal lo que le da su textura y su singularidad: la novedad es el rasgo más típico de la relación historia y ficción.

En tercer lugar, en este desarrollo de la novela histórica decimonónica, Lukács evidencia que los hechos son interpretables y su devenir incognoscible, es decir, no hay leyes que describan la naturaleza del acontecer histórico, en tanto su naturaleza universal es la singularidad de la actividad de los individuos, la que se imprime en su devenir.

En cuarto lugar, habría que destacar la importancia que adquiere para Lukács la representación de lo popular, en tanto motor histórico ignorado por el historicismo. El potencial histórico de esta representación poética, Lukács la expresa trayendo a colación las palabras de Heine (como se citó en Lukács, 1971): “Extraño capricho del pueblo! Exige su historia de la mano del poeta, no de la del historiador. No quiere un fiel relato de los hechos secos, sino los hechos que, disueltos en poesía original, son causa de aquellos" (p. 63).

Lo popular y lo poético estarían desde la poesía épica en un vínculo funcional; de alguna manera el pasado desde el cual el pueblo funda su presente y perspectiva su futuro es un pasado relatado poéticamente. La novela histórica romántica de Walter Scott sería el anudamiento de poesía, pueblo e historia que, a diferencia de la antigua épica, incluye el lugar del individuo común y corriente como el punto de contacto de la historia con lo popular. En este sentido, para Lukács la novela histórica no tiene como único referente de lo histórico lo que hoy conocemos como la versión oficial de la historia, sino la relación misma que el pueblo mantiene con lo histórico, relación que condiciona a toda actividad humana. Así las cosas, la novela histórica del siglo XIX se sitúa en un momento en el que la práctica de la historiografía aún no terminaba de consolidarse como ciencia y, por lo tanto, no hegemonizaba los posibles sentidos de lo histórico. Por esta razón, aún se podía entender que lo histórico, lo poético y lo popular se cruzaran en la forma textual de la novela. Es necesario especificar que en la articulación detectada por Lukács (2010) entre historia, pueblo y poesía hay una particularidad dada por el paradigma epistémico y existencial propio de la novela, el cual estaría dado por:

La autonomía de la vida interior es posible y necesaria sólo cuando las distinciones entre los hombres han creado un abismo insalvable; cuando los dioses se han vuelto silenciosos y ni los sacrificios ni el exultante talento del habla pueden resolver el enigma; cuando el mundo de los hechos se separa del hombre y como resultado de esa independencia se vuelve vacío e incapaz de absorber el verdadero signifi- 
cado de los hechos en sí mismos, incapaz de convertirse en símbolo a través de los hechos y de fundir a éstos a su vez en símbolos; cuando la interioridad y la aventura se divorcian para siempre. (pp. 60-61)

El individuo, por lo tanto, es representación no de la totalidad del pueblo, sino del abismo o la herida que él mismo es, separado ya del mundo de la aventura épica, del todo social. Es a través de esta fractura que el texto de la novela le da forma a un pueblo cuya relación con la historia es el signo de la pérdida de una totalidad. Podríamos señalar muchas posibles causas de esto: la disolución del vínculo con lo sagrado; la secularización de la vida; la conciencia liberal burguesa; el cambio en la relación con la tierra a partir de la revolución industrial; la explotación; etc. Me gustaría destacar aquí especialmente uno, que parece ser además el que ha generado el punto de discusión sobre lo viable o no de definir a un género histórico como NNH. Me refiero a la conformación de los estados nacionales en todo el mundo occidental y, por consiguiente, la consolidación de una historiografía que, mediante el relato de su fundación, legitimará la existencia de dichos estados como modos efectivos de organización política. La legitimidad de la historiografía nacional ya no pasa únicamente por una discusión sobre el estatuto epistemológico del conocimiento de la verdad histórica que emergería de este tipo de discurso, sino de su eficacia para realizar un anudamiento, ahora entre Estado, pueblo y pasado. Bajo mi punto de vista, será el pueblo el signo que, manteniéndose vacío en este nudo de a tres, encarnará a la mirada crítica el cuerpo del silencio, de la herida -o abismo como lo llamaba Lukács- puesto que ni el talento del habla poética podrá resolver el problema de su origen y su pertenencia con el relato historicista. En otras palabras, el pueblo será la herida histórica a suturar y, por esa misma razón, la fuente de su dinamismo creativo.

\section{LA NUEVA NOVELA HISTÓRICA}

El trabajo fundacional que le dio sus características y derecho a existencia a la categoría Nueva Novela Histórica (NNH) fue el del estadounidense Seymour Menton (1993), con su trabajo titulado La Nueva Novela Histórica de la América Latina 1979-1992, el cual parte con una extensa lista de títulos encabezada por la siguiente aclaración:

Las siguientes listas de 367 novelas históricas publicadas entre 1949 y 1992 aparecerían normalmente en un apéndice. Al ubicarlas en el "prepéndice" quiero llamar la atención a mi preferencia por la investigación que se basa en los datos empíricos más que en las divagaciones teóricas. En el caso específico de la Nueva Novela Histórica (NNH) de la América Latina entre 1979 y 1992, este subgénero no brotó como 
el resultado de un manifiesto literario ni yo me interesé en él al leer algún texto teórico sobre la marginación de la cultura popular por las fuerzas hegemónicas. (p. 11)

Y antes de comenzar la lista de novela señala:

De ahí que preparé varias ponencias en 1989 y las lancé tricontinentalmente en 1990 con la esperanza de ampliarlas e incorporarlas en toda una armada que estaría lista para navegar para el 12 de Octubre de 1992... o tal vez de 1993. (pp. 11-12)

La aparente neutralidad objetiva dada por "los datos empíricos" en el trabajo crítico de Menton haría emerger una categoría que, por sus palabras, ha aparecido casi naturalmente ante su mirada. Sin embargo, la segunda cita deja ver una coincidencia que si no tiene implicancias políticas explícitas y provocadoras, entonces quizás este trabajo no sea más que una mala lectura de una categoría completamente necesaria. El quinto centenario de la llegada de los súbditos de la corona española a América es una fecha que recuerda esa "marginación de la cultura popular por las fuerzas hegemónicas", fenómeno que es parte del suelo histórico de América Latina y uno de los acontecimientos implicado en el desarrollo de toda la época moderna, aspecto que Menton señala no incidir en la construcción de este subgénero. En esta perspectiva, lo Ilamativo de estas novelas es que (como el mismo Menton lo reconoce con la provocación del Quinto Centenario) elaboran poéticamente ${ }^{2}$ las historias generadas desde antes de la formación de los estados nacionales latinoamericanos, esto es, desde su condición de colonialidad, margen y desvío.

Desde este ejercicio crítico Menton genera a continuación una vasta lista de novelas ordenadas cronológicamente de acuerdo a su fecha de publicación. Además, sería interesante agregar que la lista está dividida en dos: las Nuevas Novelas Históricas y la Novelas Históricas Tradicionales publicadas en el mismo periodo de tiempo (19491992), siendo estas últimas más de la mitad de las novelas de esta lista. Rescato del catastro realizado por Menton que ponga de manifiesto la profusa producción de novelas históricas en las últimas décadas del siglo XX. Este hecho debería representar un asunto que no nos deje indiferentes, pues surge la pregunta sobre hasta qué punto la elaboración del material histórico es un interés permanente de la literatura latinoamericana.

No obstante, la categoría propuesta por Menton sería un marco estrecho para establecer el anudamiento de lo literario y lo histórico. Lo primero que llama la atención es una prehistoria de este subgénero, que se situaría el año 1949 con la publicación de El

2 Entendiendo, lo poético como poiesis, esto es, creación. 
reino de este mundo (Carpentier, 1992) como la primera NNH. Sin embargo, esta novela no es por sí sola suficiente para dar inicio a un subgénero histórico. En este sentido, Menton (1993) señala otros títulos que habrían sido anticipos evidentes:

Aunque la fecha definitiva de 1979 está totalmente justificada como el punto de partida para el auge de la NNH, otras dos novelas sobresalientes que cuentas los mismos rasgos se publicaron unos pocos años antes: Yo el Supremo (1974) de Augusto Roa Bastos y Terra nostra (1975) de Carlos Fuentes. (p. 31)

Los rasgos a los que hace referencia la cita y que compartirían las NNH tienen como primera condición el darse en novelas que refieran a acontecimientos históricos que hayan transcurrido en un pasado que el autor no ha podido experimentar directamente. Esta condición Menton la establece desde lo planteado por Anderson Imbert (1952), para quien las novelas que tratan momentos históricos contemporáneos a la autora o autor, no serían novelas históricas, en tanto la distancia temporal sería una condición necesaria para formar conciencia histórica. Este punto no es un dato menor, aunque Menton no se detiene a explicar la necesidad de este criterio e Imbert sólo considera condición necesaria para diferenciarlo de lo contemporáneo (de lo que se entiende que esto último no se considera como historia propiamente tal). Es necesario agregar que cuando hay distancia temporal entre un texto y el acontecimiento histórico referido, hay asimismo una serie de textualidades (historiográficas, políticas, culturales, artísticas, simbolizaciones, etc.) mediando entre el texto y los hechos. En definitiva, la mediación de una serie de discursos que dotan de múltiples formas al referente. La relación entre sujeto y pasado se sostiene tanto en las experiencias que siendo individuales son asimismo colectivas, como en un saber sobre el pasado mediado por todos aquellos documentos de la cultura que constituyen su historicidad también.

Por otro lado, las diversas elaboraciones de la historia que realiza la literatura latinoamericana, para Menton e Imbert, serían prácticas privilegiadas para realizar una lectura política y crítica. Es en este sentido precisamente crítico que Menton establece algunos rasgos que definen a una NNH, los que revisaremos para establecer aquello nos resulte útil o inútil.

En primer lugar, establece la "subordinación [...] de la reproducción mimética de cierto periodo histórico a la presentación de algunas ideas filosóficas" (Menton, 1993. p. 42). Podríamos considerar que no es una condición excluyente el que para transmitir una idea filosófica se deba necesariamente sacrificar la mímesis en la representación. Por ejemplo, no podríamos negar que la narrativa naturalista de Zolá transmite ideas afines al pensamiento filosófico de izquierda de fines del siglo XIX, lo mismo que la 
novela social chilena, lo que no excluye que se represente miméticamente la realidad histórica. La relación entre la representación de la realidad histórica y la presentación de ideas filosóficas ha sido tratada en mayor profundidad por Fernando Aínsa (1995), quien plantea que la complejidad del discurso novelesco por las técnicas narrativas surgidas en el siglo XX (fragmentación, corriente de la conciencia, montaje, etc.) permitiría una representación de lo histórico que se abre al propio espesar de la realidad al señalar que:

La complejidad histórica, muchas veces simplificada, cuando no reflejada en forma reductora y maniquea en el discurso político, histórico o ensayístico, aparece mejor reflejada en la mímesis del narrativo. La literatura tolera las contradicciones, la riqueza y la polivalencia en que se traduce la complejidad social y sicológica de pueblos, individuos, lo que no siempre sucede en el ensayo histórico, en general más dependiente del modelo teórico e ideológico al que aparece referido. (p. 113)

El primer rasgo propuesto por Menton parece estrecho, en cambio, Aínsa propone un punto de vista que incorpora posibilidades dadas por el tratamiento estético. Si se representa de manera fragmentada la realidad, no es sólo bajo la lógica de someterla a la representación de alguna idea, sino que la fragmentación es una forma propia de la cualidad fragmentada de la realidad. Así resulta que ningún abismo separaría la realidad de las ideas, y podrían estar de hecho íntimamente implicadas. Habría que apuntar aquí que la creación literaria permite libertades que el tratamiento disciplinario de la historiografía no, especialmente estando esta tan acechada por el principio de veracidad y los intereses del poder. Parece, no obstante, necesario desnaturalizar la distinción entre historiografía y literatura, para poder así establecer diferencias entre las experiencias epistémicas implicadas en la lectura, por un lado, de un texto historiográfico sobre el dictador López de Francia y, por otro lado, de la novela Yo el Supremo (Roa Bastos, 2009).

En este punto entramos en un conflicto interesante que ha generado una serie de ideas en torno a lo que la NNH aportaría como crítica política del discurso historiográfico. Mientras el historicismo sería por vocación hegemonizante, la NNH sería crítica. Para cumplir con esta función crítica, Menton (1993) afirma que las NNH utilizarían las técnicas bajtinianas de lo dialógico, lo carnavalesco y la parodia. A estos se suman rasgos propios de la novela contemporánea como la metaficción. Todos recursos que usados para ficcionalizar a grandes personajes (Cristóbal Colón, Magallanes, entre otros) subvierten la historiografía oficial. Hay críticos que incluso han instalado a la NNH como el mecanismo crítico privilegiado para desestabilizar el edificio del historicismo 
nacionalista, confundiendo la particularidad de este tipo de práctica historiográfica (claramente defendida por una ideología hegemónica) con todo el resto de la disciplina historiográfica. Sin duda que el aparataje teórico propuesto por Menton tiene como uno de sus puntos fundamentales la oposición NNH e historiografía oficial. Sin embargo, esta oposición termina en ocasiones enfrentando a la disciplina historiográfica en su conjunto con el arte literario, disolviendo en cada caso su especificidad. Una indistinción generada por la crítica posestructuralista, que muchas veces ha terminado por disolver el objeto literario en un objeto de la cultura, como afirma Werner Mackenbach (2008). Por esta razón, resulta fundamental que algunos valiosos conceptos importados de Europa -como lo polifónico, lo dialógico, lo carnavalesco-sean revisados, pues no son sencillamente asimilables al fenómeno de la opresión política que se da en los pueblos latinoamericanos, sino que deben ser distinguidos a partir de la vida que cobrarían en estas literaturas. A pesar de categorías que abstractamente son asimilables, las implicancias de trasladarlas sin someterlas a un examen histórico y cultural, termina comprometiendo la historicidad misma de estos textos. Si intentamos develar lo "nuevo" y lo "histórico" de la forma textual de las novelas históricas contemporáneas, debemos examinar que nuestro aparato de lectura no se sostenga en valoraciones que terminen ocultando su singularidad. No resultaría descabellado que las utilidades que se le den a lo carnavalesco, lo dialógico, lo polifónico y lo monológico puedan encontrar no un único sentido crítico. La polifonía, por ejemplo, no es un rasgo que emerja necesariamente cuando estemos en presencia de distintas voces en un texto. Lo que puede aparecer bajo el signo de la diversidad, puede ser también una variación de lo mismo. En el caso de Yo el Supremo, el mismo Roa Bastos (2009) ha asegurado que su novela se trataría de un "monólogo del poder". Podría parecer extraño que a una novela que presenta una clara polifonía se le asigne la categoría de "monólogo". Sin embargo, la forma de polifonía debe ser cuidadosamente examinada, porque múltiples voces pueden estar sirviendo a una misma unidad, esto es, a la multiplicidad de lo único, que es de hecho uno de los mecanismos más interesantes que tiene el poder para mantenerse vigente y volver deseable cierto orden de cosas.

Aínsa (1995) plantea la misma oposición entre el discurso de la historiografía y el de la NNH, enfrentando poder hegemónico a actividad crítica y deconstructiva. Sin embargo, para él las categorías de lectura adecuadas estarían determinadas por los aspectos paródicos de este tipo de narrativa. La elaboración del material histórico, entonces, partirían de un gesto base que consiste en desatar el vínculo de lo histórico con lo verídico para así posibilitar la entrada de la complejidad de la compresión de la realidad histórica: 
Al releer "críticamente" la historia, la literatura es capaz de plantear con franqueza y sentido crítico lo que no quiere o no puede hacer la historia que se pretende científica. La narrativa llega incluso a "suplir las amplias deficiencias de una historiografía tradicional, conservadora y prejuiciada, para la cual los problemas son siempre menores, y no pasan de ser locales", dando voz a lo que la historia ha negado, silenciado o perseguido. (p. 120)

Es difícil no estar de acuerdo con la fundamentación de Aínsa. Sin duda, las posibilidades expresivas de la literatura son menos restringidas que las de la historiografía oficial para comunicar la complejidad de las experiencias históricas. La producción literaria puede incluir aspectos singulares de la vida de los personajes históricos, los que a la vista de un historiador preocupado de los grandes procesos colectivos y políticos no serían tan importantes e influyentes. Rescatamos, por esta razón, lo señalado por Aínsa cuando destaca la posibilidad abierta en la narrativa a lo multiforme de la realidad, condición que se encuentra dada por la multiplicidad implicada en cada experiencia (una misma persona puede variar su apreciación del pasado en múltiples ocasiones a lo largo de su vida). Kristeva (1981) define este potencial de lo múltiple a propósito de lo que ella denomina el régimen del signo que rige a la novela moderna, enfrentado al régimen del símbolo propio de las sociedades pre-modernas:

La función no-disyuntiva del enunciado novelesco se opone a la disyunción exclusiva del símbolo y da pruebas del esfuerzo del pensamiento occidental por acceder a la dialéctica. Sólo en la novela tiene lugar el intento de pensar los dos términos opuestos de un modo orgánico, estructural, como siendo también, aunque lo sean en un segundo tiempo, equivalentes. (p. 266)

El signo como una realidad de dos caras -significante y significado- unidas por un vínculo arbitrario comporta lo no-disyuntivo, en tanto no se basa en la alternativa "lo uno o lo otro" del símbolo (sentido unívoco), sino en la simultaneidad de "lo uno y lo otro". En consecuencia, no habría una jerarquía de valores que instituya la elección de un vínculo intencionado por sobre otro, pues es el frágil engrudo de la arbitrariedad el que anuda estas dos realidades. Mirado desde esta perspectiva, este régimen es dialéctico, puesto que no implica la negación de lo otro, sino su inclusión. Esto en la novela queda de manifiesto en su potencial polisémico. En Yo el Supremo, se integran tanto los monólogos interiores en tono paródico, como el propio discurso oficial de la historiografía, los cuales no compiten por el predominio discursivo; la figura del Compilador mantiene el proceso dialéctico en el que ambos registros textuales sencillamente conviven, sin que ninguno refute definitivamente al otro. 
Todas estas consideraciones están en el corazón del vínculo que establece la literatura con lo histórico. Lo no-disyuntivo exige una mirada del proceso de sentido (la significación) y no del corte homogeneizador del significado que conserva una jerarquía de valores. Esto último representa el caso del concepto bajtiniano del carnaval democrático medieval (bajo el régimen del símbolo) en el que lo otro se inscribe dentro de la jerarquía de lo alto y lo bajo, cuyo componente crítico del orden hegemónico es precisamente su posibilidad de invertir la valoración, manteniendo intacta la existencia de dicho orden, eso sí ahora el poderoso es degradado y el marginal ungido rey. Muchas NNH suspenden la necesidad de jerarquizar y nos instalan en el campo imaginario de lo uno y lo otro, por lo que el carnaval bajtiniano encuentra límites a su pura aplicación. Además, en este campo imaginario la significación puede ser parte integrante del proceso de producción de lo histórico y no sólo estar ahí para negarle validez y vigencia al discurso oficial.

Hasta aquí hemos argumentado la estrechez e inutilidad del marco de lectura ofrecido por Menton que considera a la NNH como un artefacto privilegiado de la crítica. En definitiva, no se niega el aspecto crítico que se rescata desde esta teorización, pero también sería necesario que dicho aspecto recoja la forma en la que la novela histórica produce significancias o elabora la historia y, de este modo, participa del proceso histórico.

\section{LA NUEVA NOVELA HISTÓRICA COMO DESMITIFICACIÓN DE LA VERDAD HISTÓRICA}

En cuanto a los mecanismos de estas novelas, [...] destaca el frecuente uso de la parodia, la ironía, lo grotesco o el humor; la intertextualidad o la especularidad del texto sobre sí mismo; la presentación de personajes históricos cuya imagen polemiza con la de las crónicas, o la de personajes anónimos que cobran una importancia impensada; el uso, con diversos fines y de variadas maneras, de modalidades históricas tradicionales y de toda una batería de documentos y fuentes referenciales. Todo ello con el objeto de desmitificar, cuestionar y reemplazar las certezas respecto del pasado por preguntas que lleven a quebrar las lógicas causales que se han impuesto como las únicas posibles. (Viu, 2007, p. 169)

Hayden White denomina a esa poética de la historiografía "metahistoria”. Esas tres presuposiciones comprenden un desplazamiento de la problemática, pues colocan a la historia en el espacio de la ficción narrativa. La metahistoria intenta considerar los relatos históricos como ficciones verbales próximas a su contrapartida 
literaria. Se trata de saber si se puede reclasificar a la historia como artificio literario sin descalificarla como conocimiento científico. (Mignon, 1996, p. 16)

El pilar fundamental del marco de lectura propuesto para la NNH tiene relación con una conceptualización específica de la historiografía: la verdad histórica. Desde una consideración de sus recursos novelescos predominantes, se establece que estos apuntan a una desviación sistemática de la convención de veracidad propia de la historiografía. Esto arrastra consigo una crítica al corazón, ya no de la construcción discursiva que es la historiografía, sino de la propia conciencia histórica de los individuos que deben ahora enfrentarse tanto a los discursos como a las prácticas (políticas, sociales, pedagógicas, artística, morales, etc.) desde la idea de que no existe la verdad. Esto tiene como efecto que los individuos a lo sumo podremos habitar en una amplia diversidad de interpretaciones convivientes, que bajo la normatividad del sentido común de la democracia neoliberal esgrime que "cada opinión es válida", liquidando así toda tensión y todo conflicto.

A partir de este problema, han surgido corrientes historiográficas críticas que han optado por mantener una postura de constante auto-observación de sus presupuestos científicos. Se hace necesario que, siempre que establezcamos la crítica hacia el discurso oficial, no se vuelva la "historiografía" el nombre de otra indistinción en el que entran prácticas discursivas nacionalistas y sesgadas y corrientes historiográficas críticas de dicha historiografía oficial:

En los años recientes, un gran número de académicos han desafiado y puesto en duda abiertamente la veracidad del conocimiento producido por los historiadores. Algunos han ido hasta el final de este camino, argumentando que esa veracidad es intrínsecamente imposible, pero otros simplemente argumentan que deberíamos de ser muy cautelosos al afirmar algo respecto de este valor de verdad [...]

Así que los historiadores no son más que personas que se encuentran comprometidas en la gran tarea social de construir interpretaciones plausibles de la realidad social, interpretaciones que se espera que todos nosotros consideraremos útiles, no sólo individualmente sino también colectivamente. (Wallerstein, 2004, p. 46)

Una disciplina como la historiografía no puede constituirse en una verdad sobre la historia, porque la historicidad de la vida social e individual no se juega únicamente en la representación de prácticas discursivas, menos en una única representación. Estas prácticas discursivas a lo más podrían aportar a un saber, pero la verdad depende sobre todo de las prácticas de los sujetos en la historia. El marxismo en este sentido 
nos ha legado una útil distinción: una cosa es la historiografía y otra cosa es la historia. Sin duda, se trata de dos realidades de una misma experiencia que encierra su máxima complejidad en ser el nombre (historia) del cruce entre lo que Ricouer (2008) llama el tiempo individual y el tiempo histórico o comunitario. Más allá de lo que la oficialidad pueda o no dictar, la neurosis controladora de un discurso unificante no puede aniquilar la multiplicidad que es el proceso histórico, también multiplicado y especularizado en toda esa larga lista de narrativas históricas que inventarió Menton. Las corrientes historiográficas críticas del siglo XX (historia social, microhistoria, historia de la vida cotidiana, nueva historia, historiografías marxistas, entre otras) han relevado la siguiente verdad en sus prácticas disciplinarias: el concepto de historia desarrollado por la modernidad crítica es el marco conceptual desde el cual se piensa la verdad del devenir como subjetividades que crean formas de existencias singulares, cuya relación está marcada por el signo de lo múltiple y de la transformación.

En esta perspectiva, es la historicidad bajo la organización del Estado nacional lo que deviene en relato artificioso. Y así las obras consideradas como NNH no sólo desmitificarían el discurso oficial que ha generado una idea falsa bajo el nombre verdad histórica, inhabilitando así la existencia de todo el resto de las interpretaciones posibles; también permitirian imaginar retroactivamente cualquier vida que haya participado en el juego de la historia, en el tiempo colectivo. Así, muchas de estas novelas ( $L a$ guerra del fin del mundo de Mario Vargas Llosa, por poner un ejemplo) le dan forma a la construcción de lo posible; a la elaboración de lo que aún no ha llegado a ser. En la propia voz de Roa Bastos (1990) estos posibles asumen una función positiva: "La verdadera realidad no es para mí sino lo real de lo que todavía no existe." (p. 23)

Más allá de la naturalización ideológica del discurso oficial, existe la verdad de lo que está constantemente por venir, lo cual niega críticamente cualquier enquistamiento ideológico del relato nacional que intenta anular su carácter de hecho provisorio. Así, la imaginación histórica de Roa Bastos nos propone una apertura temporal que es condición perfecta para volver a crear la historia, operando con esa misteriosa fórmula en la que el pasado aún está por ser, y es que este no perteneciéndole a nadie, es de todos. Estamos, en consecuencia, ante un proceso. Cabría preguntarse si este proceso es un continuo o está, por el contrario, marcado por interrupciones, también conceptualizadas en la teoría de la NNH como "traumas" (Elmore, 1997), esto es, una poderosa experiencia que colectivizada ha transformado la representación de la verdad histórica en una forma de subsumir lo múltiple a lo uno, propia de los regímenes totalitarios. Esto se debe a que el sólo hecho de proponer una verdad (histórica, política, 
artística, etcétera) correría el riesgo de someter la libertad individual al desarrollo de una forma específica de lo colectivo, de este sometimiento surgiría el trauma. Este se formalizaría en la NNH a partir de los recursos textuales que desviando el sentido (ironía, parodia) o pluralizándolo (polifonía, carnavalización, intertextualidad) ponen de manifiesto cómo resulta imposible reducir la totalidad múltiple y compleja a la representación unívoca del discurso oficial y nacional. Sin duda, no podemos estar menos que de acuerdo con esta función crítica, no obstante, debemos reconsiderar conceptos que pluralizando los sentidos nos permitan resituar lo político ya no solo como la práctica de leer lo crítico en tanto negación del status quo, sino también como la construcción creativa de posibilidades. En este sentido, es importante relevar que una de las formas de describir el cosmos literario de América Latina ha sido el de una identidad esquiva a la conceptualización, prolífica en construirse sus múltiples rostros. Así es como lo reconoce Antonio Cándido (1987): “Todos nosotros sabemos, sin necesidad de citar a Fanon, que cuando dominamos el lenguaje del conquistador empezamos a poder conquistar al conquistador. Esto, desde mi punto de vista, es el hecho central de la literatura en América Latina" (p. 169).

El lenguaje poético de la novela presenta el trauma para poder pensarlo, ir más allá de él y reformularlo, condición de ambigüedad propia de la literatura latinoamericana para Cándido. Dicha ambigüedad estaría dada por todas las posibilidades de lo que puede llegar a hacer el conquistado cuando domina las herramientas del conquistador. Le otorga, por tanto, a la "desmitificación" histórica que propone la NNH una mayor complejidad. La NNH elabora esta desmitificación como la disposición propia de los signos novelescos a revelar la oposición binaria "ilusión de verdad" de la historiografía y "verdad de la ilusión" del discurso ficcional. No obstante, queda aún pendiente poder observar lo que el pasado puede llegar ser o lo real que todavía no es de Roa Bastos. Lo que se llama "desmitificación" de la verdad histórica, para Cándido es más bien la cualidad propia de una creación literaria que dialécticamente reproduce la relación conquistador -conquistado más allá de cualquier valorización (de lo primero y lo tercero, de lo victorioso y lo perdedor). La ambigüedad es la condición de la libertad creativa en la que tanto el conquistador como el conquistado son fuerzas constituyentes. De este modo, si hablamos de desmitificación, debemos a su vez desestabilizar la idea que instala al primer mundo como un lugar que no estaría también marcado por su potencial heterogeneidad. 


\section{A MODO DE CIERRE}

Hasta aquí, el rodeo a la categoría de la NNH ha intentado generar algunas distinciones que parecen importantes al momento de abordar el anudamiento de la ficción y la historia y la utilidad de ciertos aparatajes teóricos que muchas veces cuentan con una validez fuera de toda discusión. El aspecto crítico y político de las NNH, según hemos analizado, no se reduce a la oposición "verdad absoluta" versus "ilusión de la verdad". Esto último implicaría adjudicarle a la ficción el ser una política parasitaria, en tanto para ser crítica debe dialogar con el discurso oficial. A mi juicio, el gesto paródico es más complejo aún: es el reconocimiento de un discurso efectivamente existente con el que se dialoga directamente y del que no se puede soslayar su existencia y su efectividad con solo deconstruirlo, hay que también recrearlo. Por ejemplo, en El reino de este mundo de Carpentier, aun siendo bastante fiel a los datos de la historiografía oficial, la magia envuelve sus formas y las rehace.

A partir de esta aproximación crítica a la NNH, nos damos cuenta de lo insuficiente e incluso lo estéril que resulta tomar el carácter histórico de estas obras como mero diálogo con los discursos históricos. Es indudable que las construcciones discursivas son parte fundamental, en cuanto documentos, de la historicidad que elaboran las novelas históricas. No obstante, no se puede reducir la producción de lo histórico en la narrativa contemporánea a su diálogo con otros discursos. Sería necesario agregar entonces que es posible plantear lo anterior en la medida que la imaginación novelesca de lo histórico nos permite dar forma a un referente, pero para ver qué pasaría si este tuviese una forma poética y fuese, por lo tanto, otra cosa en relación a lo que ya fue. El flujo o devenir del tiempo se encuentra en la escritura novelesca abierto a la reelaboración y esta posibilidad de producir lo histórico que ofrece dicha escritura participa en la construcción de lo posible, de lo que todavía no existe. Lo pasado, entonces, no refiere sólo a los hechos acontecidos, a las construcciones simbólicas naturalizadas y a los emblemas sacralizados, sino a la posibilidad de su reinvención, o como señala el epígrafe de este estudio evocando a Nietzsche, a rehacer "las formas destruidas".

De parte de la historiografía, sería necesario recalcar que no se puede criticar a una disciplina por su carácter "científico" y su visión positivista pasada. En la actualidad, el concepto científico de objetividad se ha visto a lo menos relativizado. El objeto es alterado por la mirada del observador, lo que no genera la pérdida del objeto, sino que el sujeto pase a ser un dato de la observación. Podríamos aventurar que incluso eso le da cierto realce y anima a esos objetos que antes parecían muertos. Nada más pertinente para el tema que hemos discutido en el que sobre todo hemos estado hablando de 
vidas humanas y sus figuraciones literarias. Es imposible -y esto alivia bastante- que cualquier experimentación científica no tengan un espesor vital, en otras palabras, el dato de la existencia de la mirada es un momento ineludible en la conformación de todo saber, lo que reanima la visión de la realidad como un proceso. De esto se sigue, que no está del todo vedado que podamos aspirar a que los conocimientos, como señalaba Wallerstein (2004), permitan generar interpretaciones plausibles no sólo para construir un saber sobre la realidad, sino para poder actuar en ella. Por el contrario, un concepto de ciencia que implica al sujeto observante como parte del proceso de construcción del conocimiento aportaría a la superación de lo que Carmen Perilli (1995) reconoce como la herencia de las escuelas nomológicas del siglo XIX, las que buscaban extraer leyes y principios a partir del comportamiento histórico, ahogando toda creatividad y espontaneidad implicada en el proceso histórico. Por esta razón, es sintomática la crisis contemporánea que ha difuminado las fronteras entre las disciplinas del conocimiento y que nos tiene hoy preguntándonos cómo abordar una categoría como la novela histórica.

Las textualidades históricas son, en este sentido, mucho más que aplicación de técnicas narrativas de moda; son los modos en que la historia es inagotablemente reanimada y reapropiada. Michel de Certeau (1993), uno de los teóricos de la historia que más ha trabajado el problema de la cercanía entre la historiografía y la ficción, recalca las implicancias de las rupturas como formas temporales y provisorias de ser en la historia:

La historiografía separa en primer lugar su propio presente de un pasado, pero repite siempre el gesto de dividir. La cronología se compone de "períodos" [...] entre los cuales se traza cada vez la decisión de ser otro o de no ser más lo que se ha sido hasta entonces [...]. Por turno, cada tiempo "nuevo" ha dado lugar a un discurso que trata como "muerto" a todo lo que le precedía, pero que recibía un "pasado" ya marcado por rupturas anteriores. (p. 17)

El problema de la pérdida de especificidad del texto literario implica una abstracción teórica, una alienación de la práctica literaria, la cual aun así sigue siendo de hecho un trabajo diferenciado de la labor del historiador. En esta dirección se ha intentado desde la crítica literaria dar a la complejidad de los nuevos modelos de representación literaria la etiqueta de críticos, asumiendo que dicha complejidad consistiría en una práctica de negación carnavalesca del status quo, de la hegemonía, de los valores, símbolos nacionales, etc., junto con marcar su diferencia respecto a ese otro (la historiografía) que se le parece tanto que llegan a confundirse (un parecido 
potencialmente siniestro). Sin embargo, como hemos ya afirmado a lo largo de este estudio, hacer descansar toda la politicidad de las novelas históricas solo en la operatoria de desestabilización del discurso oficial es un acto de reducción que, intentando hacerse cargo de la amplitud que evidencian estas novelas, terminan por estrechar el campo de acción social de las NNH a una posición negativa respecto a su otro radical. Se instala así una disputa entre disciplinas que no deja entrever otros horizontes para anudar lo político, lo crítico y lo histórico en las novelas contemporáneas. Sería necesario, entonces, recordar como señalábamos al principio de este capítulo siguiendo a Lukács, que la historia no es sólo asunto de discursos disciplinarios, sino que compete a la totalidad de la vida humana y sus formas están siempre por hacerse. 


\section{REFERENCIAS BIBLIOGRÁFICAS}

Aínsa, F. (1995) La reescritura de la historia en la nueva narrativa latinoamericana. San José de Costa Rica: Facultad de Letras.

Anderson, I. (1952) Notas sobre la novela histórica en el siglo XIX. En Torres-Rioseco (ed.). La novela iberoamericana. (pp. 1-24) Albuquerque, Estados Unidos: University of New Mexico Press.

Aravena, P. (2009) Memorialismo, historiografía y política. El consumo del pasado en una época sin historia. Concepción: Ediciones Escaparates.

Cándido, A. (1987) Literatura e historia. En Pizarro, A. (Ed.) Hacia una historia de la Literatura Latinoamericana (pp. 168-173). México: El Colegio de México.

Carpentier, A. (1992) El reino de este mundo. Santiago de Chile: Universitaria.

De Certeau, M. (1993) La escritura de la historia. México: Universidad

Iberoamericana, Departamento de Historia.

Elmore, P. (1997) La fábrica de la memoria. México: Fondo de Cultura Económica.

Jitrik, N. (1995) Historia e imaginación literaria: las posibilidades de un género. Buenos Aires: Editorial Biblos.

Kristeva, J. (1981) El texto de la novela. Barcelona: Lumen.

Lukács, G. (1971) La novela histórica. México: Ediciones Era. (2010) Teoría de la novela. Argentina: Ediciones Godot.

Mackenbach, W. (Ed.) (2008) Historia y ficción en la novela centroamericana contemporánea. Honduras: Ediciones Subirana

Menton, S. (1993) La nueva novela histórica en América Latina: 1979 1992. Ciudad de México: Fondo de Cultura Económica.

Mignon, W. (Comp.) (1996) Historia, ficción y metaficción en la novela latinoamericana contemporánea. Buenos Aires: Ediciones Corregidor.

Nietzsche, F. (1994) Genealogía de la Moral. España: M.E. Editores. 
Contreras, M. (2021). Sobre la utilidad e inutilidad de la categoría nueva novela histórica. UCMaule, 60, enerojunio, 2021, 30-50. DOI: http://doi.org/10.29035/ucmaule.60.30

Perilli, C. (1995) Historiografía y ficción en la narrativa hispanoamericana. Tucumán: Universidad Nacional de Tucumán, Facultad de Filosofía y Letras.

Ricoeur, P. (2008) Tiempo histórico y tiempo individual. En Indij, G. (Ed.) Sobre el tiempo. Buenos Aires: La marca editora.

Roa Bastos, A. (2009) Yo el Supremo. Madrid: Alfaguara.

(1990) Discurso de la entrega Premio de Literatura en lengua castellana Miguel de Cervantes 1989. España: Anthropos

Viu, A. (2007) Imaginar el pasado, decir el presente. La novela histórica chilena (19852003). Santiago: RIL Editores.

Wallerstein, E. (2004). La escritura de la historia. Contrahistoria. La otra mirada de Clio, $7(2), 41-52$. 